\title{
Effect of Food Containing High Fe (Iron) Intake to Urinary Trans, Trans-muconic Acid (Tt-ma) Levels on Workers Exposed to Benzene
}

\author{
Siska Nirmawati ${ }^{1}$, Abdul Rohim Tualeka1, Annis Catur Adi ${ }^{2}$ \\ ${ }^{1}$ Departement of Occupational Health and Safety, ${ }^{2}$ De partement of Public Nutrition, \\ Airlang ga University, Surabaya Indonesia
}

\begin{abstract}
Glue is one of important material in the footwear manufacture which is contained benzene. Benzene vapour can enter body through the respiratory tract easily. Benzene is going to metabolism by CYP 2E1 in the liver to form trans, trans muconic acid (tt-MA) and going to excrete simultaneously with urine. Before formed tt-MA, benzene is oxidized to an epoxy benzene and benzene oxepin which are electrophilic. It can cause cancer by DNA adduct. The increase of the rate of benzene metabolism can increase tt-MA formation and reduce the risk of DNA adducts. Benzene metabolism can be enhanced by increasing Fe intake.

The study aims to analyze the effect of high dietary intake of Fe with the concentration of urinary trans, trans-muconic acid (tt-MA) in the shoe worker. Pre-experimental study with one group pretest posttest design was conducted and 19 subjects of this study recruited who had fulfilled the inclusion criteria.Worker characteristics (age, sex, and residence), nutritional status (body mass index), activity pattern (exposure time, exposure frequency and smoking habit), Fe absorption inhibitor consumption and benzene air level were identified. Urinary tt-MA measurement performed twice, before and after intervention. The intervention was giving meal containing high Fe for 56 hours ( 3 times/day). Weighing leftovers and recall Fe absorption inhibitor consumption was conducted in the end of every meal time.

The study result showed that Fe intake from meat had effect on alteration of urinary tt-MA level $(p<\alpha)$, while Fe intake from staple food, vegetables, eggs and nuts had no effect on alteration of urinary tt-MA level $(\mathrm{p}>\alpha)$.
\end{abstract}

Keywords: $t t-M A$, Benzene, Fe, Shoe Worker

\section{INTRODUCTION}

Informal footwear industry which is now considered as a growing industry in Indonesia. Glue is one of important material in the footwear manufacture. Benzene is an organic solvent contained in the glue which is volatile. It makes the benzene vapour enter into the body through the respiratory tract easily ${ }^{1,3}$.

The benzene content in the glue is around $1.5 \%$, but IARC (International Agency for Research on Cancer) categorizes benzene into group 1, means that this substance is proven to be carcinogenic in humans ${ }^{2,5}$. When benzene enters the body, it will first oxidized into benzene epoxy by Cytochrome P450 2E1 (CYP 2E1) enzyme. CYP 2E1 metabolize the benzene epoxy into benzene oksepin. Both benzene epoxy and benzene oksepin are metabolized into open chain benzene by the CYP to become trans, trans muconaldehid or conjugates with glutathione to form S-phenilmecapturic acid (SPMA) excreted by urine. Trans, trans muconaldehid oxidized into trans, trans muconic acid (tt-MA) then excreted by urine ${ }^{3,6,7}$. At the benzene exposure of $<1$ ppm, body tend to produce trans, trans muconic acid as a result of benzene metabolism than phenol and hydroquinone. Whereas, at the benzene exposure of $>1$ $\mathrm{ppm}$, body will form phenol than trans, trans muconic $\operatorname{acid}^{6,7}$.

CYP 2E1 is known as the main enzymes that metabolize benzene. It is found in the liver tissue. 
Benzene metabolism, at the benzene exposure of $>1 \mathrm{ppm}$, is dominated by CYP 2E1 enzyme ${ }^{8,9,10}$. The existence of CYP enzyme affects the body ability to metabolize the xenobiotic. Both the increased levels and activity of CYP led to the increased rate of xenobiotic metabolism and increases the excretion rate of xenobiotics. Those activities can reduce the toxicity effects of xenobiotics ${ }^{11}$. Therefore, the increased activity of CYP can increase the rate of benzene metabolism in the body which then led to the increased levels of benzene metabolites such as urinary tt-MA. tt-MA can be used as biomarker of benzene to describe the individual exposure to benzene or to show the body ability to metabolize benzene.

The pathways of benzene metabolism becoming tt-MA involves both CYP and Fe activity as catalyst ${ }^{3,5}$. Instead of becoming catalyst, the existence of Fe in the body is also important for the activity of CYP. This is due to $\mathrm{Fe}$ as the main components which play an important role in the activity of CYP enzyme ${ }^{12,16,17}$. Fe has ability to modulate the biochemical and toxicological action of CYP 2E 1 and therefore, the existence of Fe is enriched the CYP2E1 in microsomal ${ }^{15}$. The low concentration of $\mathrm{Fe}$ in the liver can decrease the rate of metabolism of xenobiotics, since, in the xenobiotic metabolism, $\mathrm{Fe}$ is necessary for the liver to bind to the heme, which then become a constituent of cytochrome $\mathrm{P} 450^{12}$.

It is possible that benzene enter the body of footwear craftsmen workers. It is metabolized through the high affinity pathway which tends to break the cyclic chain of benzene into the long-open chain, and therefore, it form $\mathrm{tt}-\mathrm{MA}$ as metabolite in the urine. Fe has a significant role in the metabolic pathway either as an active component of CYP or as a catalyst in the benzene cyclic chain termination.

\section{MATERIAL AND METHOD}

This study is a pre-experimental design with one group pretest and posttest. The measurements of ttMA was done before (pre-test) and after (post-test) the intervention by giving foods containing high concentration of Fe. Providing food containing high Fe was done at every mealtime, 3 times a day (morning, afternoon and evening), 8 times. The value of $\mathrm{Fe}$ in intervention based on the RDA (Recommended Daily Intake) plus $30 \%$. The posttest was performed 56 hours (the benzene clearance time) after the first intervention was carried out. The number of subjects was 19 people, not in the state of pregnancy, menstruation and postnatal, not taking medications regularly in more than one year, notconsumingalcohol, havingnormalhemoglobinlevels. Age, gender, smoking habits, nutritional status, working hours and coffee and tea consumption daily during the intervention was identified by using questionnaires, interviews and weight and height measurement. The research was conducted in 7 footwear home industry in Tambak Oso Wilangun, held in November 2016.

\section{FINDINGS}

The Characteristics of the research subjects can be seen in Table 1.

Table 1. The Characteristics of Subjects

\begin{tabular}{|c|c|c|c|c|}
\hline \multirow{2}{*}{ No } & \multirow{2}{*}{ Variable } & \multirow{2}{*}{ Category } & \multicolumn{2}{|c|}{ Result } \\
\hline & & & $\mathrm{n}$ & $\%$ \\
\hline \multirow{3}{*}{1} & \multirow{3}{*}{$\begin{array}{l}\text { Age } \\
\text { (years) }\end{array}$} & $20-40$ & 6 & 31,6 \\
\hline & & $>40-50$ & 5 & 26,3 \\
\hline & & $>50$ & 8 & 42,1 \\
\hline \multirow{2}{*}{2} & \multirow{2}{*}{ Sex } & Male & 10 & 52,6 \\
\hline & & Female & 9 & 47,4 \\
\hline \multirow{3}{*}{3} & \multirow{3}{*}{$\begin{array}{l}\text { Nutritional } \\
\text { Status } \\
\text { (BMI)* }\end{array}$} & Thin $(<18.5)$ & 1 & 5,3 \\
\hline & & Normal (18.5-25) & 8 & 42,1 \\
\hline & & Fat $(>25)$ & 10 & 52,7 \\
\hline \multirow[b]{2}{*}{4} & \multirow{2}{*}{$\begin{array}{l}\text { Working } \\
\text { Hours (hours/ } \\
\text { day) }\end{array}$} & $\leq 8$ & 5 & 26,3 \\
\hline & & $>8$ & 14 & 73,7 \\
\hline \multirow{2}{*}{5} & \multirow{2}{*}{$\begin{array}{l}\text { Smoking } \\
\text { Habit }\end{array}$} & Smoker & 8 & 42,1 \\
\hline & & Not smoker & 11 & 57,9 \\
\hline
\end{tabular}

Information: *BMI (Body Mass Index) is the ratio of weight $(\mathrm{kg})$ by the square of height (meters)

There are 8 points of the air benzene levels measurement in the 7 work locations. The measurement was conducted to determine the condition of benzene exposure in the workplace as seen in Table 2.

Table 2. The Level of Benzene in the Air

\begin{tabular}{|l|l|l|}
\hline Benzene Concentration & $\mathbf{N}$ & $\mathbf{\%}$ \\
\hline$<0,5 \mathrm{ppm}$ & 6 & $75 \%$ \\
\hline$\geq 0,5 \mathrm{ppm}$ & 2 & $25 \%$ \\
\hline Mean & $0,51 \mathrm{ppm}$ \\
\hline Standart Deviation & $0,79 \mathrm{ppm}$ \\
\hline Min-Max & $0,01-2,33 \mathrm{ppm}$ \\
\hline
\end{tabular}

* TLV Benzene: 0,5 ppm ${ }^{12}$ 
Table 2 shows the there are 2 points of measurements in which the levels of benzene in the air is above TLV (0,5 ppm).

The measurement of tt-MA levels in the urine was done 2 times, at pre-test and post-test. The post-test was performed 56 hours (time of benzene clearance) after the first meals was given. The alteration of tt-MA level based on pre-test and post-test measurements can be seen in Table 3.

Table 3. The Alteration Levels of tt-MA

\begin{tabular}{|l|l|l|}
\hline \multirow{2}{*}{$\begin{array}{l}\text { Alteration of tt-MA Levels }(\boldsymbol{\mu g} / \mathbf{g} \\
\text { kreatinin) }\end{array}$} & \multicolumn{2}{|l|}{ Result } \\
\cline { 2 - 3 } & $\mathbf{n}$ & $\mathbf{\%}$ \\
\hline$(-500)-<0$ & 6 & 31,6 \\
\hline$>0-500$ & 5 & 26,3 \\
\hline$>500$ & 8 & 42,1 \\
\hline
\end{tabular}

The mean of pre-test of urinary tt-MA levels is $515,69 \mu \mathrm{g} / \mathrm{g}$ creatinine and post-test 1019,53 $\mu \mathrm{g} / \mathrm{g}$ creatinine. The increased levels of urinary tt-MA is $503.84 \mu \mathrm{g} / \mathrm{g}$ creatinine $(97.7 \%)$. Table 3 shows that the levels of urinary tt-MA mostly increased after the intervention. The highest level of increase of urine tt$\mathrm{MA}$ is $>500 \mu \mathrm{g} / \mathrm{g}$ creatinine.

The consumption of coffee and tea daily during the administration of intervention was conducted through food recall interview. Most subjects consume coffee and do not consume tea daily during the intervention (Table 4)

Tabel 4. Coffee and Tea Consumption

\begin{tabular}{|l|l|l|l|l|}
\hline \multirow{2}{*}{ No } & \multirow{2}{*}{ Variable } & \multirow{2}{*}{ Category } & \multicolumn{2}{|l|}{ Result } \\
\cline { 3 - 5 } & & & $\mathbf{n}$ & $\mathbf{\%}$ \\
\hline \multirow{2}{*}{1} & \multirow{2}{*}{ Coffee } & consumption & 10 & 52,6 \\
\cline { 3 - 5 } & & Not consumption & 9 & 47,4 \\
\hline \multirow{2}{*}{2} & \multirow{2}{*}{ Tea } & consumption & 6 & 31,6 \\
\cline { 3 - 5 } & & Not consumption & 13 & 68,4 \\
\hline
\end{tabular}

The Fe intake obtained from the deviation calculation of the Fe concentration in the food given by using the Fe concentration of leftovers. The Fe intake from the interventions was categorized into 5 types of food (Table 5). The Fe intake during the administration of treatment was divided into two categories: less than $(<77 \% \mathrm{Fe}$ from the food given) and enough $(\geq 77 \% \mathrm{Fe}$ from the food given $)^{18 .}$
Table 5. The Intake of Fe Based on the Type of Food

\begin{tabular}{|c|c|c|c|c|}
\hline \multirow{2}{*}{ No } & \multirow{2}{*}{ Types of food } & \multirow{2}{*}{ Category } & \multicolumn{2}{|c|}{ Result } \\
\hline & & & $\mathbf{n}$ & $\%$ \\
\hline \multirow{3}{*}{1} & \multirow{3}{*}{$\begin{array}{l}\text { Staple food } \\
(\mathrm{mg})\end{array}$} & Enough & 15 & 78,9 \\
\hline & & Less & 4 & 21,1 \\
\hline & & Mean $(1,22)$ & - & - \\
\hline \multirow{3}{*}{2} & \multirow{3}{*}{ Meat (mg) } & Enough & 13 & 68,4 \\
\hline & & Less & 6 & 31,6 \\
\hline & & Mean $(7,95)$ & - & - \\
\hline \multirow{3}{*}{3} & \multirow{3}{*}{$\begin{array}{l}\text { Vegetables } \\
(\mathrm{mg})\end{array}$} & Enough & 18 & 94,7 \\
\hline & & Less & 1 & 5,3 \\
\hline & & Mean $(0,75)$ & - & - \\
\hline \multirow{3}{*}{4} & \multirow{3}{*}{ Eggs (mg) } & Enough & 17 & 89,5 \\
\hline & & Less & 2 & 10,5 \\
\hline & & Mean $(0,59)$ & - & - \\
\hline \multirow{3}{*}{5} & \multirow{3}{*}{ Nuts (mg) } & Enough & 19 & 100 \\
\hline & & Less & 0 & 0 \\
\hline & & Mean $(9,41)$ & - & - \\
\hline
\end{tabular}

The statistical test of simple linear regression was conducted for the normally distributed data and the statistical test of logistic regression was performed for the not normally distributed data. The purpose of this test is to determine the effect of $F e$ intake on the alteration levels of urinary tt-MA. The results of the statistics test can be seen in Table 6 .

Table 6. The Results of Normality Test and the Effect of Fe Intake on the Alteration Levels of Urinary tt-MA

\begin{tabular}{|l|l|l|l|}
\hline No & Types of food & p-value & Result \\
\hline 1 & Makanan Pokok & 0,751 & Insignificant \\
\hline 2 & Daging & 0,001 & Significant \\
\hline 3 & Sayuran & 1,000 & Insignificant \\
\hline 4 & Telur & 0,999 & Insignificant \\
\hline$(\alpha=0,05)$ & \multicolumn{2}{l}{} \\
\hline
\end{tabular}

The Fe intake of nuts was not tested due to the homogeneous data.

The statistical test of logistic regression was performed to determine the effect of coffee and tea consumption daily during the intervention on the changes levels of urine tt-MA (Table 7). 
Table 7. The Test Results of the Effect of Coffee and Tea Consumption on the Alteration Levels of ttMA

\begin{tabular}{|l|l|l|l|}
\hline No & Consumption & p- value & Result \\
\hline 1 & Kopi & 0,053 & Insignificant \\
\hline 2 & Teh & 0,698 & Insignificant \\
\hline$(\alpha=0,05)$ & \\
\hline
\end{tabular}

The Effect of Fe Intake on the Alteration Levels of Urinary tt-MA

Fe plays a significant role in the metabolism of benzene in the body, as an active constituent of CYP 2E1. CYP 2E1 is an enzyme that metabolizes benzene entering the body into its metabolites. The metabolism of benzene occurs in the liver and bone marrow $w^{3,6}$.

Benzene exposured can cause the increased levels of $\mathrm{Fe}$ in the liver and bone marrow. The increased levels of $\mathrm{Fe}$ indicate an increase in the metabolic activity of benzene inside those organs ${ }^{20}$. The Fe existence in the liver and bone marrow play role in metabolizing benzene through binds to apoprotein to form CYP 2E1. Fe supplementation can increase the number of cytochrome P450 in the liver to metabolize drugs ${ }^{14 .}$ Enough Fe intake help the body to metabolize benzene to form its metabolites such as tt-MA excreted from the body through urine.

This research was conducted by giving food containing high $\mathrm{Fe}$ for 56 hours to the workers exposed to benzene and it is expected to help in increasing the metabolism of xenobiotics benzene which showed by the increased levels of urinary tt-MA. There are 5 types of food as sources of $\mathrm{Fe}$ in each menu, including: staple food, eggs, vegetables, nuts and meat.

Results based on the regression test of $\mathrm{Fe}$ intake of food types on the alteration levels of urinary ttMA indicates that $\mathrm{Fe}$ intake from staple food, eggs, vegetables and nuts has no effect on the alteration level of urinary tt-MA $(p>\alpha)$. Whereas, the Fe intake from meat has an effect on the alteration levels of urine tt-MA $(\mathrm{p}<\alpha)$.

$\mathrm{Fe}$ derived from meat is heme $\mathrm{Fe}$. The bioavailability of heme $\mathrm{Fe}$ is higher than the non-heme Fe which is mostly found in the vegetative foods. The bioavailability of heme $\mathrm{Fe}$ is around $30-35 \%$. Heme $\mathrm{Fe}$ can be easily absorbed in the intestinal lumen. This is due to heme $\mathrm{Fe}$ is not affected by other nutrients which act as inhibitors of $\mathrm{Fe}$ absorption such as polyphenols and tannins from the tea or coffee. Moreover, heme Fe is soluble in the oxidizing environment in the gut. It caused by the porphyrin ring which prevents the heme $\mathrm{Fe}$ to form insoluble polymers in the environment of small intestine $^{13,19}$. Unlike heme $\mathrm{Fe}$, non heme $\mathrm{Fe}$ is easily oxidized in the gut to form long chain of polymer Fe which is insoluble so that it cannot pass through the intestinal mucous membrane to be absorbed ${ }^{13}$. It supports the regression test result of this research which indicates that consuming coffee and tea daily during the intervention does not affect the levels changes of urine tt-MA.

Heme Fe entering the intestinal mucosal cells (enterocyte) is released from the porphyrin ring by heme oxygenase enzyme. Then, $\mathrm{Fe}$ is transported across the basolateral membrane in $\mathrm{Fe}^{2+}$ form (ferrous) through ferroportin. $\mathrm{Fe}^{2+}$ is oxidized by haephestin to $\mathrm{Fe}^{3+}$ which then binds to transferrin and transported to the plasma. Through tranferin, Fe can be distributed to the liver. In the liver cells particularly inside the mitochondria, $\mathrm{Fe}$ undergo coupling reaction with protoporphyrin IX to form heme by the enzyme of ferrochelatase. This heme, which then binds to apoprotein in the endoplasmic reticulum of liver cells, to form CYP. It is going to further differentiate into families CYP $2 \mathrm{E} 1^{13^{3} 16}$. Then CYP 2E1 metabolize benzene in the liver to form tt$\mathrm{MA}^{3}$.

\section{CONCLUSION}

Fe intake from staple food, eggs, vegetables and nuts has no effect on the alteration level of urinary ttMA. Whereas, the Fe intake from meat has an effect on the alteration levels of urine tt-MA.

\section{Conflict of Interest: None}

Source of Funding : Departement of Occupational Health and Safety, Airlangga University, Surabaya Indonesia

Ethical Clearance: The study was approved by the institutional Ethical Board of the Public Health, Airlangga University.

All subjects were fully informed about the procedures and objectives of this study and each subject prior to the study signed an informed consent form. 


\section{REFERENCES}

1. Klaasen, Curtis D. Casarett \& Doull's Toxicology: The Basic Science of Poisons 6th Edition. Boston: McGraw-Hill. 2001.

2. Kurniawidjaja, L.M, Nur Aziza Sofia, Hendra, Eko Pudjadi, Fatma Lestari dan Mila Tejamaya. Keluhan Pernapasan dan Analisis Risiko Kesehatan Pajanan BTX pada Pekerja di Bengkel Alas Kaki Informal di Kecamatan Ciomas Kabupaten Bogor. Jurnal Respirologi, 32 (1): 36-43. 2012.

3. ATSDR. Toxicological Profiles for Benzene. US Department of Health and Human Service, Public Health Service, Atlanta, Georgia: Agency for Toxic Substance and Disease Registry. 2007.

4. ACGIH. Threshold Limit Value for Chemical Substances and Physical Agents and Biological Exposure Indices. Cincinnati: American Conferrence Governmental Industrial Hygienists. 2015.

5. Health Council of the Netherlands. Benzene - Health Based Recommended Occupational Exposure Limit. Report, Pub. No. 2014/03: 31-74. 2014.

6. Rappaport, Stephen M., Sungkyoon Kim, Qing Lan, Roel Vermeulen, Suramya Waidyanatha, Luoping Zhang, Guilan Li, Songnian Yin, Richard B. Hayes, Nathaniel Rothman, dan Martyn T. Smith, Evidence That Humans Metabolize Benzene via Two Pathways. Environmental Health Perspectives,117 (6): 946- 952. 2009.

7. Kim, Sungkyoon, Roel Vermeulen, Suramya Waidyanatha, Brent A. Johnson, Qing Lan, Martyn T. Smith, Luoping Zhang, Guilan Li, Min Shen, Songnian Yin, Nathaniel Rothman dan Stephen M. Rappaport. Modeling Human Metabolism of Benzene Following Occupational and Environmental Exposures. Cancer Epidemiology Biomarkers Prevention, 15(11):2246-2252. 2006.

8. Powley M.W., dan Carlson G.P. Cytochromes P450 Involved with Benzene Metabolism in Hepatic and Pulmonary Microsomes. Journal Biochemical Molecular Toxicology,14:303-309. 2000.

9. Kim, Roel Vermeulen, Suramya Waidyanatha, Brent A. Johnson, Qing Lan, Martyn T. Smith, Luoping Zhang, Guilan Li, Min Shen, Songnian Yin, Nathaniel Rothman dan Stephen M. Rappaport. Genetic Polymorphisms and Benzene Metabolism in Humans Exposed to A Wide Range of Air Concentrations. Pharmacogenet Genomics, 17:789-801. 2007.

10. Fukami T., Katoh M., Yamazaki H., Yokoi T., Nakajima M. Human Cytochrome P450 2A13 Efficiently Metabolizes Chemicals in Air Pollutants: Naphthalene, Styrene, and Toluene. Chemical Research Toxicology, 21: 720-725. 2008.

11. Delvin, Thomas M. Texbook of Biochemistry with Clinical Correlations., New York: Wiley - Liss Inc.981-997. 1993.

12. Dhur, Agnes, Pilar Galan dan Serge Hercberg. Effect of Different of Iron Deficiency on Cytochrome P450 Complex and Pentose Phosphate Pathway Dehydrogenase in the Rat. The Journal of Nutrition, 119: 40-47. 1989.

13. Caballero, Bejamin, Paul M. Finglas, dan Fidel Toldra. Encyclopedia of Food and Health. Oxford: Elsevier Ltd., 452-475. 2016.

14. Catz, Charlotte S., Mont R. Juchau dan Sumner J. Yaffe. Effect of Iron, Riboflavin, and Iodide Deficiencies on Hepatic Drug-Metabolizing Enzyme System. The Pharmacology and Experimental Therapeutic, 174(2): 197-204. 1988.

15. Cederbaum, Arthur I., (2003). Iron and CYP2E1Dependent Oxidative Stress and Toxicity. Alcohol, April, 30:115-120. 2003

16. Ortiz de Montellano, Paul R. Cytochrome P450 Structure, Mechanism, and Biochemistry. New York: Plenum Publishers. 418-421. .2005.

17. Kunze, Kent. Cytochrome P450 Catalytic Mechanisms I. MedChem 527, Winter: 3-18. 2013.

18. Gibson, R. S. Principles of Nutritional Assessment Second Edition. New York: Oxford University Press Inc. 2005.

19. European Food Safety Authority (EFSA), . Scientific Opinion on The Safety of Heme Iron (Blood Peptonates) For The Proposed Uses As A Source of Iron Added For Nutritional Purposes To Foods For The General Population, Including Food Supplements. EFSA Journal, 8(4):8-22. 2010.

20. Agrawal, Rashmi, Pankaj K. Sharma, Gondi S. Rao. Release of Iron from ferritin by metabolites of benzene and superoxide radical generating agents. Toxicology, 168: 223-230. 2001. 